\title{
West syndrome
}

INSERM

\section{Source}

INSERM. (1999). Orphanet: an online rare disease and orphan drug data base. West syndrome. ORPHA:3451

West syndrome (or infantile spasms) is characterised by the association of clusters of axial spasms, psychomotor retardation and an hypsarrhythmic interictal EEG pattern. It is the most frequent type of epileptic encephalopathy. It may occur in otherwise healthy infants and in those with abnormal cog nitive development. 